\title{
Performance evaluation of chemical coagulation process to treat bagasse wastewater: modeling and optimization
}

\author{
K. Thirugnanasambandham ${ }^{1}$, V. Sivakumar ${ }^{2 *}$ K. Shine ${ }^{3}$ \\ ${ }^{1}$ Excel College of Engineering and Technology, Department of Chemistry, Komarapalayam, Namakkal-637303, TN, India \\ ${ }^{2}$ Anna University, Department of Chemical Engineering, AC Tech Campus, Chennai-600025, TN, India \\ ${ }^{3}$ King Saud University, Department of Botany and Microbiology, College of Science, Post box 2455, Riyadh 11451, Saudi \\ Arabia \\ "Corresponding author: e-mail: drvsivakumar@yahoo.com
}

\begin{abstract}
In this present study, chemical coagulation process $(\mathrm{CC})$ treatment process was investigated under different conditions such as $\mathrm{pH}$, ferric chloride dose, agitation time and settling time to treat bagasse wastewater using response surface methodology (RSM). The outcomes were evaluated using Pareto analysis of variance (ANOVA) and second order polynomial models were created with the aim of being able to predict the responses. Ideal conditions were observed to be as per the following: agitation time of $25 \mathrm{~min}, \mathrm{pH}$ of 7, ferric chloride dose of $6 \mathrm{~g} / \mathrm{L}$ and settling time of $60 \mathrm{~min}$. Under these conditions, turbidity removal of $62 \%$, COD removal of $67 \%$, TDS removal $53 \%$ and sludge production of $32 \mathrm{~mL} / \mathrm{L}$ were obtained with operating cost of 3.50 Rupee/L. The mechanism of CC was analyzed using XRD spectrum and founds to be adsorption.
\end{abstract}

Keywords: bagasse wastewater, chemical coagulation, ferric chloride, Box-Behnken design, sludge, operation cost, optimization.

\section{INTRODUCTION}

Nowadays, water is the crucial part in any and all paper industries. It is used almost in every step of paper making procedure, which certainly picks up the unwanted and sometimes harmful wastes ${ }^{1}$. Therefore, paper industries are considered to be the main pollution threats in India with concern to wastewater regulation, since these produce huge quantity of waste streams that are dangerous to the ecological system ${ }^{2}$. The United States Environmental Protection Agency (USEPA) and the Central Pollution Control Board of India (CPCB) made a stringent regulations to discharge the paper industry wastewater ${ }^{3}$. However, there is still a greater need to decrease the amount of pollutants from paper wastewaters by using the newer methods for clean and safe industrial processes ${ }^{4}$. Most paper industries in India use wood as the main raw material and bagasse as an alternative potential raw material for the paper manufacture, due to the limited availability of wood. Bagasse is the fibrous residue remaining after sugarcane crushed to extract their juice and is a "waste" from the sugar industries. In addition of some advantages in uses of bagasse for producing pulp, there are few practical complications in the form of collection and storing of bagasse due to its seasonal availability. Bagasse stored under wet condition by spraying water to preserve its quality, which uses large quantity of water and produce an effluent called bagasse wastewater ${ }^{5}$. Discharge of this wastewater causes negative impact on receiving water bodies. Therefore, there is a crucial need to design the environment friendly and economically viable method to treat bagasse wastewater.

Last few decades, treatment operations include adsorption, oxidation, ozonation, photocatalysis, biological and chemical coagulation were in various wastewater treatment plant (WTP). Each technique has its own merits and demerits in application ${ }^{6}$. As of late, Chemical coagulation treatment procedure has warranted a significant amount of consideration for providing high removal proficiency in the treatment of wastewater; this procedure can be specifically practiced on waste waters to eliminate organics as well as suspended solids ${ }^{7}$. In essence, chemical coagulation (CC) is one of the emerging technique for eliminating the colloidal types of pollution from waste water and for decreasing chemical oxygen demand (COD). This method comprises of destabilizing colloids, amassing and binding them to each other into flocculates; the flocs that occur can at long last be isolated either by settling or by flotation ${ }^{8}$. The destabilization process entails initially a raise in ionic strength which encourages dual-layered pressure, and/or the balance of the molecule surface charge by adsorbing counter anions, making use of the inclusion of chemicals known as coagulants. During the process of wastewater treatment, the normally utilized coagulants are hydrolysable metal salts; these are efficient for the process of destabilizing colloidal particles, as almost all colloids are charged negatively in ordinary waters and industrial effluents: the coagulant for the most part was ferric chloride $\left(\mathrm{FeCl}_{3}\right)$ that are readily soluble in water. Meanwhile, many factors can influence CC treatment efficiency, such as the agitation time, coagulant dose, $\mathrm{pH}$ and settling time. Optimization of these process variables significantly increase the process efficiency with reasonable operating cost ${ }^{9}$.

In conventional multi-factor tests, optimization is generally performed by changing single variant whereas keeping all other variants constant ${ }^{10}$. It is time-taking and usually incompetent of realization the true optimum, because of ignoring the interactive effect among process parameters. Response surface methodology (RSM) is a statistical strategy for experimental design, structuring models, assessing the impacts of different variants, and looking for optimal conditions for attractive responses ${ }^{11}$. However, to the best of our knowledge, chemical coagulation treatment technique to treat bagasse wastewater using RSM has not yet reported in literature. Therefore, in this research work the efficiency of CC process to treat bagasse wastewater was investigated under different conditions such as agitation time, $\mathrm{pH}$, ferric chloride 
dose and settling time using Box-Behnken design (BBD). Finally, the quality of produced sludge and operating cost was examined for its practical implementation.

\section{MATERIAL AND METHODS}

Wastewater was collected from a local paper industry TamilNadu, India and it was storedin $4^{\circ} \mathrm{C}$ in order to avoid the changes in composite wastewater. Analytical reagent grade chemicals such as Hydrochloric acid $(\mathrm{HCl})$ and sodium hydroxide $(\mathrm{NaOH})$ were used, which was supplied by local suppliers, Erode.

A conventional batch studies were performed under various operating conditions include agitation time, coagulant dose, initial $\mathrm{pH}$ and settling time in $2.5 \mathrm{~L}$ of beaker containing $1.6 \mathrm{~L}$ of composite wastewater. Magnetic stirrer was used to agitate the sample. After the treatment, sample was centrifuged at $6500 \mathrm{rpm}$ for 15 min (Remi R-24 Centrifuge, India) and the supernatant was filtered through a $0.45 \mu \mathrm{m}$ filter papers and the filtrate was collected. Then, it was used to analyze the reduction in turbidity, chemical oxygen demand (COD) and total dissolved solids (TDS). Each trials was carried out in triplicates and the outcomes were exhibited as the mean value of the triplicates

Physico-chemical properties of the wastewater such as $\mathrm{pH}$, turbidity, COD and TDS were find out according to the APHA standard procedure explained in elsewhere ${ }^{12}$. The removal efficiency was calculated as follows ${ }^{13}$

$\mathrm{RE}=\left(\frac{\mathrm{c}_{0}-\mathrm{c}_{\mathrm{e}}}{\mathrm{c}_{0}}\right) \times 100$

where, $c_{0}$ and $c_{e}$ is the initial and final concentrations of turbidity, COD and TDS, respectively. Operating cost of $\mathrm{CC}$ process was calculated using unit price of $\mathrm{FeCl}_{3} \cdot 6 \mathrm{H}_{2} \mathrm{O}$ price $(0.58$ Rupee/g) according to Merck chemicals, Chennai.

In this recent research, Box-Behnken response surface design (BBD) with four components at three different levels was utilized for optimization and examine the impact of procedure variables, for example, agitation time (A), $\mathrm{pH}$ (B), ferric chloride dose (C) and settling time (D) on chemical coagulation $(\mathrm{CC})$ treatment process to obtain a maximum treatment efficiency from bagasse wastewater. Process factors and their levels (Table 2) were find out based on the preliminary studies ${ }^{14}$. Experimental runs were prepared based on a BBD and the design consists of 29 trials with five center points were designed. Then the Design-Expert 8.0.7.1 (State-Ease Inc., Minneapolis, MN, USA) statistical package was used for the statistical

Table 2. Process variables and their ranges

\begin{tabular}{|l|l|}
\hline Characteristics & Bagasse wastewater \\
\hline $\mathrm{pH}$ & 7.5 \\
\hline Turbidity & $1768 \mathrm{NTU}$ \\
\hline Chemical oxygen demand [COD] & $6500 \mathrm{mg} / \mathrm{L}$ \\
\hline Total dissolved solids [TDS] & $4525 \mathrm{mg} / \mathrm{L}$ \\
\hline
\end{tabular}

Table 1. Characteristics of bagasse wastewater

\begin{tabular}{|l|r|r|r|}
\hline \multirow{2}{*}{ Process variables } & \multicolumn{3}{|c|}{ Level } \\
\cline { 2 - 4 } & -1 & 0 & 1 \\
\hline Agitation time [A, min] & 15 & 25 & 35 \\
\hline Initial pH [B] & 6 & 8 & 10 \\
\hline Ferric chloride dose [C, g/L] & 2 & 4 & 6 \\
\hline Settling time [D, min] & 20 & 40 & 60 \\
\hline
\end{tabular}

calculations. The correlation between the responses and four independent factors were assessed by building up the second order polynomial scientific models and the summed up type of mathematical equation was given as follows ${ }^{15}$.

$Y=\beta_{0}+\sum_{j=1}^{k} \beta_{j} X_{j}+\sum_{j=1}^{k} \beta_{i j} X_{j}^{2}+\sum_{i} \sum_{j=2}^{k} \beta_{i j} X_{i} X_{j}+e_{i}$

Sufficiency of created model was studied by the pareto analysis of variance (ANOVA). Regression coefficients of these second order polynomial models and their effects were analyzed with the help of the F-values at probability levels $(p \leq 0.05)$. The experimental data were analysed with various statistical analysis such as determination coefficient (R2), adequate precision (AP) and coefficient of variation $(\mathrm{CV})$ to emulate the statistical significance of the developed polynomial equations ${ }^{16}$. After that, the individual and interactive impacts of treatment parameters on reaction were concentrated on $3 \mathrm{D}$ response surface graph from created numerical models. Optimization of treatment factors for the most effective treatment productivity was completed by Derringer's desired function strategy utilizing numerical optimizing technique ${ }^{17}$.

\section{RESULTS AND DISCUSSION}

In this work, evaluation of chemical coagulation (CC) process to treat bagasse wastewater was investigated under various operating conditions using statistical method RSM coupled with BBD for the maximum efficiency of the bagasse wastewater treatment. BBD experimental design consists of 29 experiments were carried out and the results were shown in Table 3. The responses presented in Table 3 were correlated with the four independent factors utilizing a polynomial mathematical statement, Eq. (2). Least squares regression was employed to correlate with the acquired result to Eq. (2). The best fit models in the coded factors as follows:

$\mathrm{Y}_{1}=67.84-2.32 \mathrm{~A}+2.80 \mathrm{~B}+0.38 \mathrm{C}+21.56 \mathrm{D}+$ $+2.25 \mathrm{AB}-1.64 \mathrm{AC}-6.51 \mathrm{AD}-8.24 \mathrm{BC}+1.85 \mathrm{BD}-$ $-1.83 \mathrm{CD}-19.86 \mathrm{~A} 2-19.50 \mathrm{~B} 2-5.93 \mathrm{C} 2-19.85 \mathrm{D} 2(3)$ $\mathrm{Y}_{2}=72.26-2.26 \mathrm{~A}+2.80 \mathrm{~B}+0.40 \mathrm{C}+21.60 \mathrm{D}+$ $+2.22 \mathrm{AB}-1.65 \mathrm{AC}-6.51 \mathrm{AD}-8.25 \mathrm{BC}+1.95 \mathrm{BD}-$ $-1.83 \mathrm{CD}-19.82 \mathrm{~A} 2-19.41 \mathrm{~B} 2-6.00 \mathrm{C} 2-19.85 \mathrm{D} 2 \quad$ (4) $\mathrm{Y}_{3}=51.42-1.24 \mathrm{~A}-2.23 \mathrm{~B}-4.96 \mathrm{C}-17.28 \mathrm{D}-1.26 \mathrm{AB}-$ $-1.45 \mathrm{AC}-1.49 \mathrm{AD}-10.42 \mathrm{BC}+2.18 \mathrm{BD}+6.33 \mathrm{CD}-$ $-17.67 \mathrm{~A} 2-17.46 \mathrm{~B} 2-11.87 \mathrm{C} 2-15.00 \mathrm{D} 2$

$\mathrm{Y}_{4}=43.00-0.83 \mathrm{~A}+0.33 \mathrm{~B}-0.92 \mathrm{C}+3.25 \mathrm{D}-0.25 \mathrm{AB}-$ $-0.25 \mathrm{AC}-2.00 \mathrm{AD}-1.25 \mathrm{BC}+0.50 \mathrm{BD}-2.75 \mathrm{CD}-$ $-6.50 \mathrm{~A} 2-7.00 \mathrm{~B} 2-4.13 \mathrm{C} 2-5.88 \mathrm{D} 2$

Where $\mathrm{Y}_{1}, \mathrm{Y}_{2}, \mathrm{Y}_{3}$ and $\mathrm{Y}_{4}$ are turbidity removal (\%), COD removal (\%), TDS removal (\%) and sludge production $(\mathrm{mL} / \mathrm{L})$ respectively. ANOVA evaluations of these models, imply that the developed models can describe the chemical coagulation process significantly. Adequacy of the developed model fit the experimental values, the parameters F-value, $\mathrm{R}^{2}, \mathrm{p}$-value, $\mathrm{CV}$ and $\mathrm{AP}$ values were used ${ }^{18}$. As can be seen in results, $F$-values of four responses such as $\mathrm{Y}_{1}, \mathrm{Y}_{2}, \mathrm{Y}_{3}$ and $\mathrm{Y}_{4}$ implied that the developed quadratic model was significant. Also, each term in the models are also examined for significance ${ }^{19}$. A p-value smaller than 0.05 implies that 
Table 3. BBD experimental design with results

\begin{tabular}{|c|c|c|c|c|c|c|c|c|}
\hline Run & A & $B$ & C & $D$ & $Y_{1}$ & $Y_{2}$ & $\mathrm{Y}_{3}$ & $Y_{4}$ \\
\hline 1 & 25 & 6 & 6 & 40 & 48.51 & 52.95 & 32.12 & 32 \\
\hline 2 & 25 & 6 & 4 & 20 & 8.54 & 12.94 & 4.56 & 28 \\
\hline 3 & 15 & 6 & 4 & 40 & 31.53 & 35.98 & 15.12 & 30 \\
\hline 4 & 15 & 10 & 4 & 40 & 32.54 & 36.96 & 16.12 & 31 \\
\hline 5 & 15 & 8 & 4 & 20 & 2.52 & 6.92 & 3.71 & 27 \\
\hline 6 & 35 & 10 & 4 & 40 & 27.64 & 32.32 & 11.22 & 29 \\
\hline 7 & 25 & 10 & 6 & 40 & 37.58 & 41.93 & 21.12 & 30 \\
\hline 8 & 25 & 8 & 2 & 20 & 16.32 & 20.68 & 2.65 & 28 \\
\hline 9 & 35 & 8 & 6 & 40 & 42.54 & 46.95 & 26.12 & 32 \\
\hline 10 & 25 & 8 & 4 & 40 & 67.84 & 72.26 & 51.42 & 43 \\
\hline 11 & 25 & 10 & 2 & 40 & 52.59 & 56.94 & 36.12 & 34 \\
\hline 12 & 25 & 6 & 4 & 60 & 45.24 & 49.67 & 28.82 & 31 \\
\hline 13 & 25 & 8 & 6 & 20 & 17.54 & 21.92 & 1.12 & 29 \\
\hline 14 & 25 & 8 & 4 & 40 & 67.84 & 72.26 & 51.42 & 43 \\
\hline 15 & 35 & 8 & 4 & 60 & 40.52 & 44.96 & 34 & 30 \\
\hline 16 & 25 & 8 & 4 & 40 & 67.84 & 72.26 & 51.42 & 43 \\
\hline 17 & 35 & 8 & 2 & 40 & 42.54 & 46.93 & 16.24 & 32 \\
\hline 18 & 25 & 8 & 6 & 60 & 61.87 & 66.28 & 55.42 & 33 \\
\hline 19 & 25 & 8 & 4 & 40 & 67.84 & 72.26 & 51.43 & 43 \\
\hline 20 & 25 & 10 & 4 & 20 & 10.54 & 14.95 & 5.24 & 28 \\
\hline 21 & 15 & 8 & 2 & 40 & 40.78 & 45.14 & 15.25 & 32 \\
\hline 22 & 35 & 6 & 4 & 40 & 17.64 & 22.45 & 15.25 & 29 \\
\hline 23 & 35 & 8 & 4 & 20 & 12.55 & 16.96 & 3.56 & 28 \\
\hline 24 & 25 & 6 & 2 & 40 & 30.54 & 34.98 & 5.42 & 31 \\
\hline 25 & 25 & 10 & 4 & 60 & 54.64 & 59.48 & 38.22 & 33 \\
\hline 26 & 25 & 8 & 2 & 60 & 67.98 & 72.34 & 31.61 & 43 \\
\hline 27 & 15 & 8 & 4 & 60 & 56.54 & 60.94 & 40.12 & 37 \\
\hline 28 & 25 & 8 & 4 & 40 & 67.86 & 72.26 & 51.42 & 43 \\
\hline 29 & 15 & 8 & 6 & 40 & 47.34 & 51.76 & 30.92 & 33 \\
\hline
\end{tabular}

the corresponding model term is highly significant. From ANOVA results, it is clear that the linear terms for $\mathrm{A}$, $\mathrm{B}, \mathrm{C}$ and $\mathrm{D}$ have large effects on responses, due to high $\mathrm{F}$-values. The p-values $<0.0001$ show that there is only a $0.01 \%$ chance that a model F-value this large is the product of noise in the conducted experiments ${ }^{20}$. In addition, the linear term for B and D is also significant but with a smaller effect of $\mathrm{A}$ and $\mathrm{C}$ on the response $\mathrm{Y}_{4}$, due to its smaller F-value. However, the linear term for the independent variables except $\mathrm{A}$ has a large $\mathrm{F}$-value and a $\mathrm{p}$-value $<0.05$ for $\mathrm{Y}_{1}-\mathrm{Y}_{3}$. The quadratic terms for all the responses are not significant but with F-values smaller than their corresponding linear terms. But, the interactive term of $\mathrm{BD}$ for all the responses is significant and other terms are not significant ${ }^{21}$. These results indicates that the suggested model is an appropriate description of the chemical coagulation (CC) process. The obtained regression equations and coefficient of determination were evaluated to test the fit of developed models. Actual values are data for each specific run from Table 3, and predicted values are created by the model, Eq. (3-6). In experimental design, $\mathrm{R}^{2}$ is a calculation of amount of variation around the mean explained by the developed models. On the other hand, a large value of $\mathrm{R}^{2}$ can be misleading if the model contains extraneous terms ${ }^{22}$. By adding factors to the models, correlation coefficient $\left(\mathrm{R}^{2}\right)$ always increases whether the added factor is significant or not. The data in Figure 2 clearly shows that the adjusted determination coefficient is very high to prove the high significance of the developed mathematical models. The goodness of fit of the model was also evaluated by the adequate precicion (AP) and co-efficient of variance (CV), which clearly stated that, the differences between experimental and predicted values are low and confirms the reliability of the conducted experiment ${ }^{23}$. The obtained results indicates that the developed mathematical has the ability to explain the chemical coagulation process very robustly.
$3 \mathrm{D}$ response surface graphs were created to evaluate the interactive and individual effects of factors for the maximize the bagasse wastewater treatment efficiency ${ }^{24}$, which were shown in Figures 1-2.

Mixing time is one of the major factor for the treatment of bagasse wastewater using CC process, which is associated with treatment efficiency. In order to investigate the effect of agitation time on CC process, experiments were carried out various agitation time (15, 25 and 35 min) and results are shown in Figure 1. The result showed that turbidity removal, COD removal, TDS removal and sludge production are increased with agitation time upto $30 \mathrm{~min}$. This phenomenon could be described by fact that, at higher agitation time increases the collisions between coagulant and the colloidal particle present in the wastewater, thus treatment efficiency is decreased ${ }^{\mathbf{2 5}}$. Beyond the agitation time of $30 \mathrm{~min}$ shows the negligible effect on the treatment efficiency of CC process for the bagasse wastewater.

$\mathrm{pH}$ is one of the crucial factor, which affects the CC process to treat bagasse wastewater. So that, experiments were done to investigate the effect of $\mathrm{pH}(6,8$ and 10) over the CC treatment process and the results was presented in Figure 1. The result showed that, the turbidity removal, COD removal, TDS removal and sludge production are increased linearly with increasing $\mathrm{pH}$ from 6-8. This because of the increase in $\mathrm{pH}$ would increase the $\mathrm{Fe}(\mathrm{OH})_{3}$ species, which has the strong affinity towards colloidal particle in the bagasse waste water to be treated, which leads to the increase in treatment efficiency ${ }^{\mathbf{2 6}}$. Thereafter, there is a formation of $\mathrm{Fe}(\mathrm{OH}) 4^{-}$which is insoluble in wastewater, thus treatment efficiency is decreased beyond $\mathrm{pH}$ of 7 .

Ferric chloride dose is also an important factor influences the $\mathrm{CC}$ process to treat bagasse wastewater. Therefore, in this study influence of ferric chloride on the $\mathrm{CC}$ treatment process was examined by varying its range $(2,4$ and $6 \mathrm{~g} / \mathrm{L})$ and the results are illustrated in 

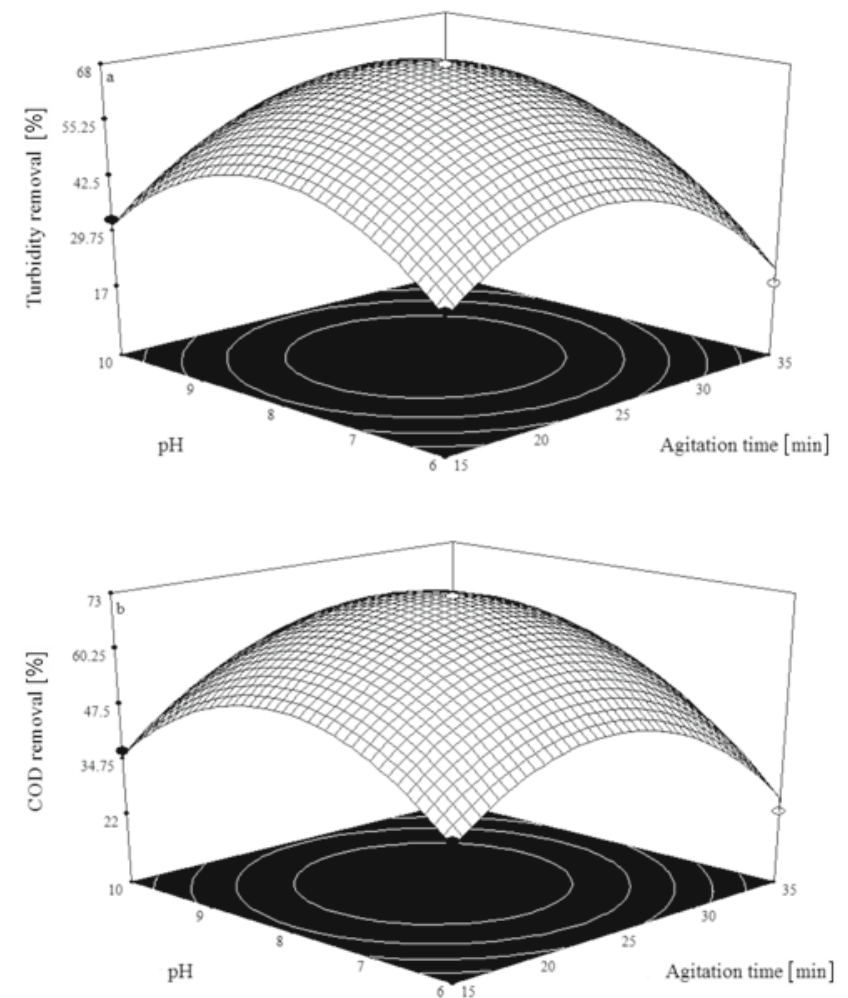
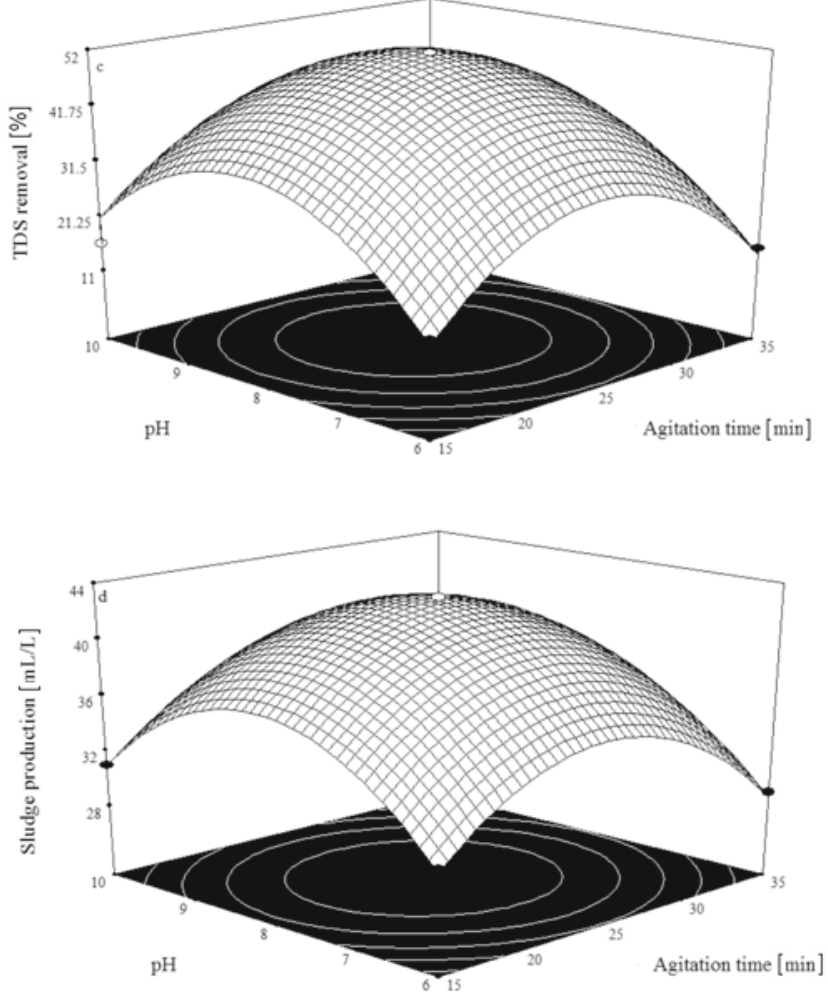

Figure 1. Response surface plots representing the effect of process variables (A \& B) on CC process
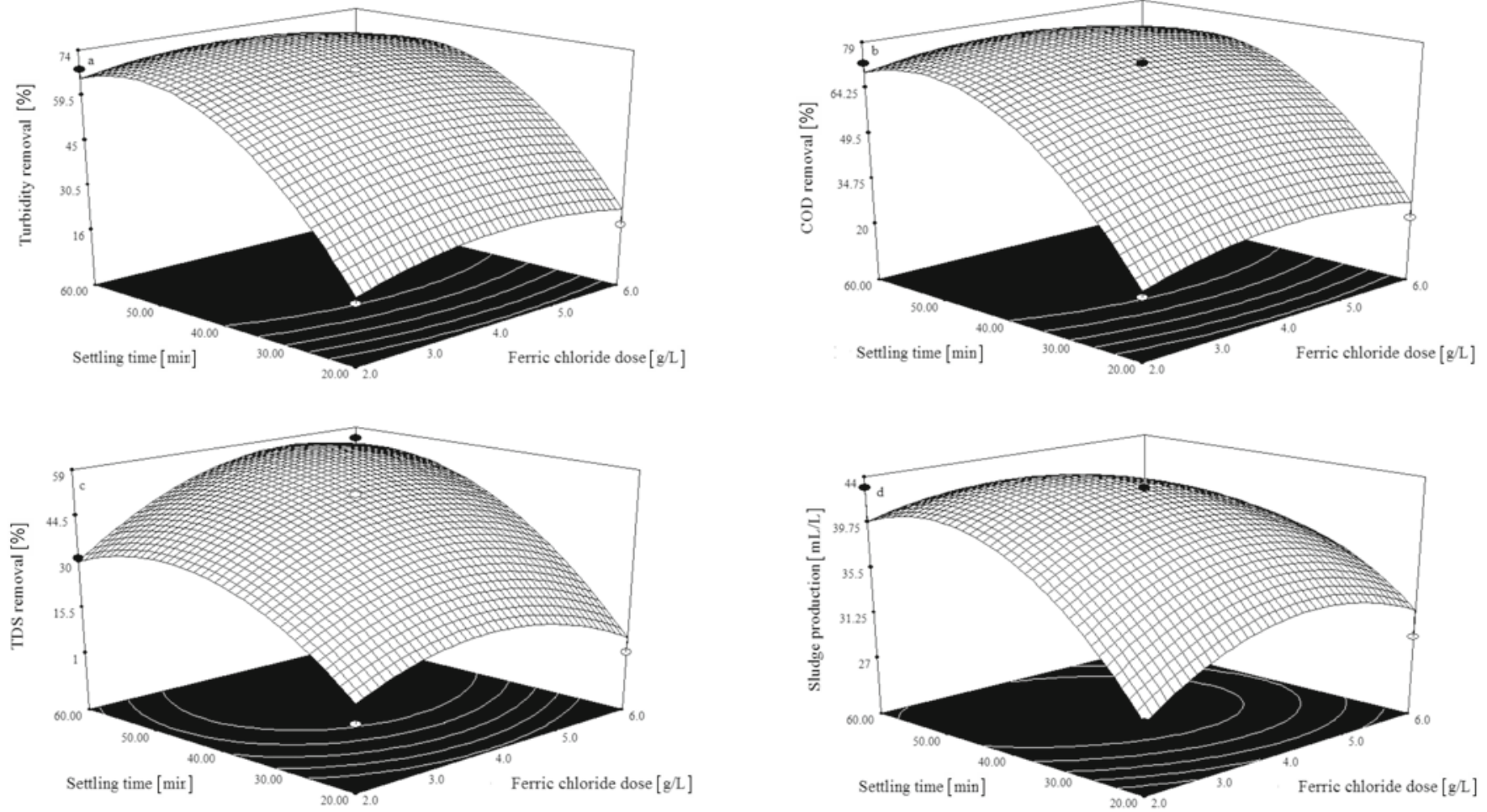

Figure 2. Response surface plots representing the effect of process variables $(C \& D)$ on CC process

Figure 2. The result showed that turbidity removal, COD removal, TDS removal and sludge production are increased with the increasing ferric chloride dose throughout the experiment. It is because of the increase in ferric chloride dose increases the formation of larger active $\mathrm{Fe}(\mathrm{OH})_{3}$ species which increase the treatment efficiency ${ }^{27}$.

Efficiency of CC process to treat bagasse wastewater is extremely affected by settling time and its influence are investigated by varying settling time $(20,40$ and $60 \mathrm{~min}$ ) and the results are depicted in Figure 2. The result showed that, turbidity removal, COD removal, TDS removal and sludge production are increased with the increasing settling time upto $50 \mathrm{~min}$ and it can be described by the fact that increase in settling time increases the formation of larger flocs, thus effiency of $\mathrm{CC}$ process is increased. Beyond the settling time of 50 min shows the decreased treatment efficiency due to the negative impact of formation or aggregation of flocs ${ }^{28}$.

Concurrent optimization of the various responses was done making use of Derringer's desired function proce- 
dure so as to investigate the ideal operating conditions for the most efficient treatment of CC method to treat bagasse wastewater ${ }^{29,} \mathbf{3 0}$. This will enhance any mix of one or more objectives; these could be either process factors or responses ${ }^{\mathbf{3 1}, \mathbf{3 2}}$. The conceivable objectives are: minimize, maximize, within range, target, none (for just responses alone) and tuned to a specific value (only variables). In this current research, objectives of the process parameters were chosen as in an extent and the response objective was chosen as maximize; with the exception of sludge generation. This numerical optimization method assesses a point that boosts the attractive capabilities and ideal conditions were observed to be as per the following: agitation time of $25 \mathrm{~min}, \mathrm{pH}$ of 7 , ferric chloride dose of $6 \mathrm{~g} / \mathrm{L}$ and settling time of 60 min. Under these conditions, turbidity removal of $62 \%$, COD removal of $67 \%$, TDS removal $53 \%$ and sludge production of $32 \mathrm{~mL} / \mathrm{L}$ were obtained with operating cost of 3.50 Rupee/L with a desirability value of 0.999 . Subsequently, the correctness of ideal conditions for anticipating ideal responses values are tested taking into account the aforementioned conditions. Triplicate analyses were done under the optimized conditions and the mean values $(<3 \%$ error) gotten from real experiment, exhibited the approval of the optimized parameters ${ }^{33}$.

To confirm the mechanism of CC process, the composition of the sludge produced by chemical coagulation was analyzed using X-ray diffraction (XRD) spectrum at the optimum process conditions. As seen in Figure 3 , the strongest peaks appeared were identified to be adsorption of organic matters on to the $\mathrm{Fe}(\mathrm{OH})_{3}$. At $\mathrm{pH} 7$ amorphous $\mathrm{Fe}(\mathrm{OH})_{3}$ formed adsorb negatively charged ions and this is beneficial for a rapid adsorption of soluble compounds and colloids particles. This is the main reason for the chemical coagulation process.

\section{CONCLUSIONS}

In this study, BBD response surface design (BBD) was used to investigate and optimize the chemical coagulation (CC) process parameters includes agitation time, $\mathrm{pH}$, ferric chloride dose and settling time on the treatment of bagasse wastewater. Second order polynomial models were developed for predicting the responses with high correlation coefficient values $\left(\mathrm{R}^{2}\right)$. Optimum set of the independent variables was attained by derringer's desired

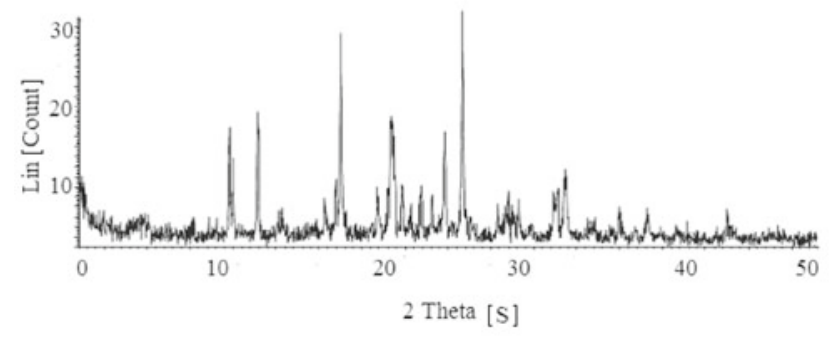

Figure 3. Experimental conversion-time profiles at different temperatures and $\mathrm{CO}_{2}$ concentrations for $\mathrm{CaO}$ from calcined $\mathrm{CaCO}_{3}$ and original $\mathrm{CaO}$

function methods and it was found to be: agitation time of $25 \mathrm{~min}, \mathrm{pH}$ of 7 , ferric chloride dose of $6 \mathrm{~g} / \mathrm{L}$ and settling time of $60 \mathrm{~min}$. Under these conditions, turbidity removal of $62 \%$, COD removal of $67 \%$, TDS removal
$53 \%$ and sludge production of $32 \mathrm{~mL} / \mathrm{L}$ were obtained with operating cost of 3.50 Rupee/L. The properties of sludge was analyzed using EDAX spectrum and it shows the higher content of trace metals.

\section{ACKNOWLEDGEMENTS}

This Project was supported by King Saud University, Deanship of Scientific Research, College of Sciences Research Center.

\section{LITERATURE CITED}

1. Chinnaraj, S, \& Venkoba Rao, V. (2006). Implementation of an UASB anaerobic digester at bagasse-based pulp and paper industry. Biomass Bioenerg 30, 273-277.

2. Thirugnanasambandham, K., Sivakumar, V. \& Prakash Maran, J. (2013). Treatment of egg processing industry effluent using chitosan as an adsorbent. J. Serb. Chem. Soc. DOI: 10.2298/JSC130201053T.

3. Sridhar, R., Sivakumar, V., Prince Immanuel, V. \& Prakash Maran J. (2011). Treatment of pulp and paper industry bleaching effluent by electrocoagulation process. J. Hazard. Mater. 186, 1495-1502.

4. Wong, S.S., Teng, T.T., Ahmada, A.L., Zuhairi, A. \& Najafpour, G. (2006). Treatment of pulp and paper mill wastewater by poly acrylamide (PAM) in polymer induced flocculation. J. Hazard. Mater. 135, 378-388. DOI: 10.1016/ j.jhazmat.2005.11.076.

5. Chiang, L., Chang, J. \& Wen, T. (1995). Indirect oxidation effect in electrochemical oxidation treatment of landfill leachate. Water Res. 29, 671. DOI: 10.1016/0043-1354(94)00146-X. 6. Wei Lung, C., Chihta, W., Wenchun, C. \& Shihyu, C. (2010). Adsorption treatment of oxide chemical mechanical polishing wastewater from a semiconductor manufacturing plant by electrocoagulation. J. Hazard. Mater. 180, 217-224.

7. Cansares, P., Martinez, F., Jimenez, C., Saez, C. \& Rodrigo, M. (2008). Coagulation and electrocoagulation of oil-in-water emulsion. J. Hazard. Mater. 151, 44-51.

8. Muftah, H.E.N., Sulaiman, A., Amal, A. \& Souzan, M. (2009). Assessment of electrocoagulation for the treatment of petroleum refinery wastewater. J. Environ. Manage 91, 180-185. 9. Thirugnanasambandham, K., Sivakumar, V. \& Prakash Maran, J. (2013). Application of chitosan as an adsorbent to treat rice mill wastewater- Mechanism, modeling and optimization. Carbohyd Polym. 97, 451-457.

10. Prakash Maran, J., Manikandan, S., Thirugnanasambandham, K., Vigna Nivetha, C. \& Dinesh, R. (2013). Box-Behnken design based statistical modeling for ultrasound-assisted extraction of corn silk polysaccharide. Carbohyd Polym. 92, 604-611. 11. Prakash Maran, J., Sivakumar, V., Thirugnanasambandham, K. \& Sridhar, R. (2013). Model development and process optimization for solvent extraction of polyphenols from red grapes using Box- Behnken design. Prep Biochem Biotech. DOI: $10.1080 / 10826068.2013 .791629$.

12. Fontanier, V., Farines, V., Albet, J., Baig, S. \& Molinier, J. (2006). Study of catalyzed ozonation for advanced treatment of pulp and paper mill effluents. Water Res. 40, 303-310. DOI: 10.1016/J.WATRES.2005.11.007.

13. Wang, B., Kong, W. \& Ma, H. (2007). Electrochemical treatment of paper mill wastewater using three-dimensional electrodes with Ti/Co/SnO2-Sb2O5anode. J. Hazard. Mater. 146, 295-301. DOI: 10.1016 /J.JHAZMAT. 2006.12.031.

14. Amat, A.M., Arques, A., Lopez, F. \& Miranda, M.A. (2005). Solar photo-catalysis to remove paper mill wastewater pollutants. Solar Energy 79, 393-401. DOI: 10.1016/ J.SOLENER.2005.02.021. 
15. Kim, S., Geissen, S. \& Vogelpohl, A. (1997). Landfill leachate treatment by a photoassisted fenton reaction, Water Sci. Technol. 35, 239. DOI: 10.1016/J.WATRES.2003.08.007. 16. APHA. (1995). Standard Methods for the Examination of Water and Wastewater. http://top-pdf.com/apha-2120-f.html 17. Shen, Z.M., Yang, Hu, X.F., Lei, Y.M., Ji, X.L., Jia, J.P. \& Wang, W.H. (2005). Dual electrodes oxidation of dye wastewater with gas diffusion cathode. Environ. Sci. Technol. 39, 1819-1826. DOI: 10.1021/es901269s.

18. Panizza, M., Bocca, C. \& Cerisola, G. (2005). Electrochemical treatment of wastewater containing polyaromatic organic pollutants. Water Res. 34, 2601-2605. DOI: 10.1021/es049730n. 19. Fahidy, T.Z. (1985). Principles of Electrocheical reactor analysis, Elsevier, Amsterdam, 136-140. www.fkit.hr/files/ dodiplomski/stari/C

20. Walsh, F.C. (2001). Electrochemical technology for environmental treatment and clean energy conversion. Pure Appl. Chem. 73, 12, 1819-1837. DOI: 10.1351/pac200173121819.

21. Ugurlu, M., Karaoglu, M.H. \& Kula, I. (2006). Experimental investigation of chemical oxygen demand, lignin and phenol removal from paper mill effluents using three-phasethreedimensional electrode reactor. Polish. J. Environ. Stud. 15, 647-654.

22. Mustoe, L.H. \& Wragg, A.A. (1981). Effects of flow and electrical arrangement on the performance of some simple electrochemical reactor systems. J. Chem. Technol. Biotechnol. 31, 317-326. DOI: 10.1002/jctb.503310143.

23. Levenspiel, O. (1999). Chemical Reaction Engineering, John Wiley \& Sons, New York. http://khup.com/keyword/ chemical- reaction-engineering-levenspiel.html

24. Dara, S.S. (1991). A Text Book of experiments and calculations - Engineering chemistry; Chand .S.and company Ltd., New Delhi. http://khup.com/keyword/engineering-chemistry-schand-publications.html

25. Dümmling, S., Eichhorn, E., Schneider, S., Speiser, B. \& Würde, M. (1996). Recycling of the Supporting Electrolyte Tetra(n-butyl)ammonium Hexafluorophosphate from Used Electrolyte Solutions. Current Separations 15, 53-56. http:// www.currentseparations.com/issues/15-2/cs15-2b.pdf

26. Nassar, M.M., Fadaly, O.A. \& Sedahmed, G.H. (1983). A new electrochemical technique for bleaching cellulose pulp. J. Appl. Electrochem. 13, 663-667. DOI: 10.1007/BF00617824. 27. Alverez-Gall Bergos, A. \& Pl Etch Er, D. (1999). The removal of low level organics via hydrogen peroxide formed in a veticulated vitreous carbon cathode cell. Part: The removal of phenols and related compounds from aqueous effluents, Electrochim. Acta. 44, 2483. DOI: 10.1016/S0043-1354(01)00147-6. 28. Chen, X., Ch En, G.H. \& Yu E, P.L. (2000). Separation of pollutants from restaurant wastewater by electrocoagulation, Sep. Purif. Technol. 19, 65. DOI: 10.1016/S1383-5866(99)00072$-6$.

29. Raghu, S. \& Ahmed Basha, C. (2007). Electrochemical treatment of Procion Black 5B using cylindrical flow reactor - A pilot plant study. J. Hazard. Mater. B139, 381-390, DOI: 10.1016/j.jhazmat.2006.06.082.

30. Sharari, M., Jahan Latibari, A., Guillet, A., Aurousseau, M., Mouhamadou, B., Rafeiee, G.H., Mirshokraei, A. \& Parsapaghouh, D. (2010). Application of the white rot fungus Phanerochaete chrysosporium in biotreatment of bagasse effluent. Biodegradation 2010. 22(2), 421-430.

31. Solanki, A.B., Parikh, J.R. \& Parikh, R.H. (2007). Formulation and optimization of piroxicam proniosomes by 3-factor, 3-level Box-Behnken design. AAPS Pharm Sci Tech. 8, 43-49. 32. Batalon, J.T. \& Madamba, P.S. (2001). Optimization of coir dust compaction using the response surface methodology approach. J. Agric. Eng. Res. 78, 167-175.

33. Bayraktar, E. (2001). Response surface optimization of the separation of DL-tryptophan using an emulsion liquid membrane, Process Biochem. 37, 169-175. 